\title{
POLÍTICA NACIONAL DO IDOSO: PERCEPÇÃO DOS GESTORES E PERFIL DOS IDOSOS DE UM MUNICÍPIO DE PEQUENO PORTE
}

\author{
National Policy on the Elderly: managers' perception and \\ profile of the elderly of a small municipality
}

\author{
Política Nacional del Mayor: percepción de gestores y el perfil \\ de mayores de un pequeño municipio
}

Artigo Original

\begin{abstract}
RESUMO
Objetivo: Identificar a percepção dos gestores municipais sobre a Política Nacional do Idoso (PNI), relacionando-a ao perfil sociodemográfico dos idosos e às estratégias de atenção à saúde em um município de pequeno porte do Rio Grande do Sul. Métodos: Trata-se de um estudo transversal, descritivo-exploratório, de abordagem quanti-qualitativa. As entrevistas foram realizadas com seis gestores de um único município e 134 idosos, identificados por questionário sociodemográfico. As entrevistas foram transcritas e analisadas a partir da análise de conteúdo. A análise estatística foi realizada no programa SPSS versão 21 , com aplicação do teste Qui-Quadrado e adotado $p<0,05$. Resultados: Ao longo das entrevistas com os gestores emerge o desconhecimento acerca da PNI, impactando no planejamento das ações. A saúde é representada a partir da ausência da doença, relacionando-a como frequente no envelhecimento. A análise estatística aponta resultados significativos na relação entre escolaridade e acesso ao serviço $(p<0,01)$ e avaliação dos idosos sobre os serviços $(p=0,00)$. Conclusão: A falta de conhecimento dos gestores no que se refere à PNI impacta diretamente nas ações de saúde para esse ciclo de vida no município. Os idosos eram, na sua maioria, do sexo feminino, com ensino fundamental incompleto, aposentados que usavam unidade básica de saúde e que não identificavam seu papel de controle social para o planejamento de ações que sejam de seu interesse.
\end{abstract}

Descritores: Idoso; Gestão em Saúde; Políticas Públicas.

\section{ABSTRACT}

Objective: The aim of this study was to identify the municipal managers' perception of the National Policy on the Elderly (Politica Nacional do Idoso), relating this policy to the sociodemographic profile of the elderly, and health care strategies in a small municipality of Rio Grande do Sul. Methods: This is s a descriptive and exploratory cross-sectional study of quantitative and qualitative approach. The interviews were carried out with six health managers of a single municipality and 134 elderly, identified by means of a sociodemographic questionnaire. The interviews were transcribed and analyzed using the content analysis method. Statistical analysis was performed using the software SPSS version 21. The Chisquare test was performed, adopting $p<0.05$. Results: Through the interviews with health managers, the ignorance of the PNI has emerged, impacting on health planning. Health is represented based on the absence of disease, being related as frequent in aging. The statistical analysis points out significant results in the association between educational level and access to the service $(p<0.01)$ and the elderly's evaluation about the service $(p=0.00)$. Conclusion: The managers' lack of knowledge regarding the PNI poses a direct impact on health actions for this life cycle in the municipality. The majority of the elderly were female, with incomplete elementary education, retirees who used a basic health unit and who did not identify their role as social control in the planning of actions that are of interest to them.

Descriptors: Elderly; Health Management; Public Policy.

\author{
Cássia Letícia dos Reis ${ }^{(1)}$ \\ Lydia Christmann Espindola \\ Koetz ${ }^{(1)}$ \\ Eduardo Périco ${ }^{(1)}$
}

\begin{abstract}
1) Centro Universitário Univates UNIVATES - Lajeado - RS - Brasil.
\end{abstract}

Recebido em: 10/04/2016 Revisado em: 05/08/2016 Aceito em: 28/11/2016 


\section{RESUMEN}

Objetivo: El objetivo de ese estudio fue identificar la percepción de los gestores municipales sobre la Politica Nacional del Mayor (PNM) relacionándola con el perfil sociodemográfico de los mayores y las estrategias de atención en salud de un pequeño municipio de Rio Grande do Sul. Métodos: Se trata de un estudio transversal, descriptivo-exploratorio, de abordaje cuanticualitativo. Las entrevistas se realizaron con seis gestores de un solo municipio y 134 mayores identificados por un cuestionario sociodemográfico. Las entrevistas fueron trascritas y analizadas a partir del análisis de contenido. El análisis estadístico fue realizado en el programa SPSS versión 21. Fue realizada la prueba de Chi-cuadrado y adoptado el $p<0,05$. Resultados: A lo largo de las entrevistas con los gestores emerge el desconocimiento sobre la PNM lo que impacta en el planeamiento de las acciones. La salud está representada a partir de la ausencia de la enfermedad relacionándola como frecuente en el envejecimiento. El análisis estadístico señala resultados significativos en la relación entre la escolaridad y el acceso al servicio $(p<0,01)$ y la evaluación de los mayores sobre los servicios $(p=0,00)$. Conclusión: La ausencia de conocimiento de parte de los gestores sobre la PNM tiene impacto directo en las acciones de salud para ese ciclo de vida del municipio. Los mayores eran, en su mayoría, del sexo femenino con educación primaria incompleta, jubilados que frecuentaban la unidad básica de salud y no identificaban su papel de control social para el planeamiento de acciones que sean de su interés.

Descriptores: Anciano; Gestión en Salud; Políticas Públicas.

\section{INTRODUÇÃO}

Os municípios com até 15.000 habitantes representam uma parcela expressiva do cenário brasileiro. Nas regiões Sul e Centro-Oeste, aproximadamente $60 \%$ dos municípios são pequenos. Na região Sudoeste, essa média permanece próxima aos mesmos valores, em torno de $55 \%$. Nas regiões Norte e Nordeste, essa porcentagem é menor, porém não menos expressiva, $46 \%$ e $39 \%$, respectivamente, são compostas por municípios com população inferior a 12.000 habitantes. No Rio Grande do Sul, esses municípios representam $74 \%$ dos 497 municípios que o compõem ${ }^{(1)}$.

São nos pequenos municípios que, geralmente, se concentram as porcentagens mais elevadas da população idosa. Visto isso, vale ressaltar que o processo de envelhecer vai além das alterações fisiológicas, compreende também a percepção do próprio idoso sobre as mudanças que ocorrem em sua vida nos mais diferentes aspectos: físico, emocional, social, entre outros ${ }^{(2,3)}$. Assim, o aumento no número de idosos é disparador para mudanças nos serviços ofertados para essa população(4).

A partir do aumento do número de idosos na população brasileira, a política de saúde do idoso é elaborada. A Lei
8.842 foi promulgada em 1994 e dispõe sobre a Política Nacional do Idoso (PNI), tendo por objetivo assegurar seus direitos e estabelecer responsabilidades nos diferentes níveis de atenção, com foco na autonomia, integração e participação efetiva do idoso na sociedade ${ }^{(5)}$. Em 2003, com a publicação do Estatuto do Idoso, a proteção aos idosos é incrementada no país, visando contemplar o idoso em seus diferentes aspectos e garantindo-lhes direitos específicos, como os deveres das famílias, das instituições, do Estado e do cidadão na atenção aos cuidados e apoio ao idoso. No entanto, são poucos os idosos que têm acesso ou conhecimento sobre essas informações ${ }^{(6-8)}$

Em 2012, no município abordado, a população com 60 anos ou mais representava mais de $12 \%$ da população, e a tendência é que esse número aumente para as próximas décadas não apenas em nível nacional, mas mundial. Consequentemente, um novo perfil epidemiológico da população vem surgindo e leva à mobilização do país na organização e definição de políticas públicas ${ }^{(9)}$.

Conhecer o perfil sociodemográfico dos idosos de determinado local permite elaborar um plano de ação eficaz, que atenda às perspectivas e às necessidades dos idosos. A participação da população em todas as fases de desenvolvimento e realização é de grande valia, pois conhecer as crenças, valores e significados em relação à promoção da saúde, bem como o papel da fisioterapia no processo, proporciona maior entendimento sobre os aspectos que influenciam na vida das pessoas ${ }^{(10)}$.

A promoção de saúde só se faz possível quando identificamos a população e os fatores de risco a que estão sujeitas. Por sua vez, a promoção da saúde só ocorre efetivamente se os gestores responsáveis pela elaboração e aplicação de políticas públicas a entenderem como importante no cuidado em saúde, já que a transição demográfica impulsiona a necessidade de estudos que possam nortear o cuidado de forma ampla e integral atendendo aos conceitos básicos redefinidos pela Portaria $\mathrm{n}^{\mathrm{o}} 2.446$ de $2014^{(11)}$.

Com base no exposto, este estudo teve por objetivo identificar a percepção dos gestores municipais sobre a PNI, relacionando-a ao perfil sóciodemográfico dos idosos e as estratégias de atenção à saúde em um município de pequeno porte do Rio Grande do Sul.

\section{MÉTODOS}

Este estudo caracteriza-se como transversal, descritivoexploratório, de abordagem quanti-qualitativa. Foi realizado em um município de pequeno porte, localizado no Vale do Taquari, no interior do estado do Rio Grande do Sul, com aproximadamente 12 mil habitantes. Emancipado há 55 anos, o município, apesar de colonizado por açorianos, 
possui grande parte da população de origem alemã. A coleta de dados ocorreu nos meses de agosto e setembro de 2014.

A pesquisa qualitativa consistiu na aplicação de entrevistas realizadas com 6 gestores das seguintes áreas: saúde, esporte e lazer, assistência social, e habitação, os quais, quando convidados, aceitaram participar da pesquisa e assinaram o Termo de Consentimento Livre e Esclarecido (TCLE). As entrevistas ocorreram de forma individual e no local de trabalho dos participantes. Os dados foram gravados, transcritos e analisados pela pesquisadora a partir da análise de conteúdo ${ }^{(12)}$. As entrevistas tiveram como tema a PNI, em especial os aspectos relacionados à gestão dos serviços, à participação dos usuários e às estratégias do município.
A amostra quantitativa foi obtida através da aplicação de um questionário sócio-demográfico com idosos residentes no município. Os idosos incluídos foram homens e mulheres, com 60 anos ou mais, que concordassem em participar da pesquisa. Segundo dados do IBGE, em 2012, o município em questão possuía 1566 idosos e $25 \%$ de cobertura da atenção básica. Assim, o total de idosos na área estudada e prevista era de 391. Com base nesse número, foi realizado cálculo amostral, utilizando $95 \%$ de confiança e $5 \%$ de erro amostral, totalizando 195 idosos.

A coleta de dados foi realizada pelos ACS, na casa dos idosos, no turno da manhã ou da tarde, conforme disponibilidade dos idosos. Os questionários foram preenchidos pelos idosos. Em decorrência do tempo

Tabela I - Perfil sociodemográfico dos idosos entrevistados (n=134). Vale do Taquari, RS, 2014.

\begin{tabular}{|c|c|c|}
\hline Dados sociodemográficos & $\mathbf{n}$ & $\%$ \\
\hline \multicolumn{3}{|l|}{ Sexo } \\
\hline Feminino & 101 & 75,37 \\
\hline Masculino & 33 & 24,63 \\
\hline \multicolumn{3}{|l|}{ Faixa etária } \\
\hline 60 a 70 & 79 & 58,96 \\
\hline 71 a 80 & 41 & 30,60 \\
\hline 81 a 90 & 12 & 8,95 \\
\hline 91 a 100 & 2 & 1,49 \\
\hline \multicolumn{3}{|l|}{ Escolaridade } \\
\hline Analfabeto & 8 & 5,97 \\
\hline $1^{\mathrm{a}}$ a $5^{\mathrm{a}}$ série & 107 & 79,85 \\
\hline $6^{\mathrm{a}}$ a $8^{\mathrm{a}}$ série & 11 & 8,21 \\
\hline Ensino Médio & 3 & 2,24 \\
\hline Superior & 5 & 3,73 \\
\hline \multicolumn{3}{|l|}{ Residência } \\
\hline Própria & 128 & 95,52 \\
\hline Alugada & 6 & 4,48 \\
\hline \multicolumn{3}{|l|}{ Com quem reside } \\
\hline Companheiro & 64 & 47,76 \\
\hline Sozinho & 35 & 26,12 \\
\hline Filhos & 17 & 12,68 \\
\hline Companheiro/filhos & 6 & 4,48 \\
\hline Companheiro/netos & 4 & 2,98 \\
\hline Filhos/netos & 3 & 2,24 \\
\hline Netos & 2 & 1,49 \\
\hline Companheiro/filhos/mãe & 1 & 0,75 \\
\hline Cuidadora & 1 & 0,75 \\
\hline Irmãos & 1 & 0,75 \\
\hline \multicolumn{3}{|l|}{ Fonte de Renda } \\
\hline Aposentadoria & 125 & 93,28 \\
\hline Sem fonte fixa & 5 & 3,73 \\
\hline Pensionista & 3 & 2,24 \\
\hline Salário doença & 1 & 0,75 \\
\hline
\end{tabular}


disponibilizado para coleta de dados, aqueles que não estavam em suas casas no período da coleta de dados não foram incluídos na amostra do estudo, totalizando 134 participantes.

A análise estatística foi realizada no programa SPSS, versão 21. A relação entre as variáveis foi analisada a partir do teste Qui-Quadrado e foram apresentados com média e desvio padrão. Para todos os procedimentos, foi adotada uma probabilidade de erro de $5 \%(\mathrm{p}<0,05)$.

Esta pesquisa, buscando atender aos critérios éticos, foi encaminhada ao Comitê de Ética em Pesquisa (COEP), do Centro Universitário Univates, para avaliação antes de sua aplicação, aprovada pelo protocolo 652.311 de 05/05/2014, de acordo com os regulamentos da Portaria Ministerial no. 466 de 2012 do Ministério da Saúde, ao qual compete regulamentar as pesquisas com seres humanos.

\section{RESULTADOS}

Ao analisar o perfil sociodemográfico dos idosos percebe-se que a maior parte é constituída pelo sexo feminino, na faixa de idade entre 60 e 70 anos, com escolaridade entre o primeiro e o quinto ano do Ensino Fundamental. Quanto à moradia, 47,7\% dos idosos residem em casa própria, sendo a fonte de renda principal dos idosos a aposentadoria. Ao analisar as residências, identifica-se que os idosos residem com filhos e/ou companheiros (Tabela I).

Conhecer o perfil dos idosos do município é o primeiro passo para o planejamento das ações de cuidado. Para tal, é fundamental conhecer a Política Pública de Saúde de âmbito nacional. As entrevistas analisadas demonstram o entendimento dos gestores sobre a PNI. Durante as falas, é possível identificar a forma como percebem essa articulação dentro do município, revelando a falta de conhecimento da mesma. $\mathrm{O}$ entrevistado 1 a relaciona com a consulta médica e identifica a PNI como ação setorial ao afirmar que: " [...] se define mais na área de atendimento do público que vem até aqui, essa área (a atenção aos idosos) seria mais para a assistência social ou dos Núcleos de Apoio à Atenção Básica”.

Outra categoria emergente relaciona-se ao financiamento para promoção de ações voltadas aos idosos, surgindo a percepção em relação à setorização do cuidado, bem como falta de entendimento sobre a PNI e sua aplicação, como pode ser percebido na fala do entrevistado 2: "Não tínhamos [...] nenhum programa, nenhum projeto voltado através da nossa área, da nossa secretaria, até porque isso tudo é absorvido dentro da assistência social", e complementa "todos os projetos dos grupos de terceira idade, grupo de mães principalmente, os grupos que são da ginástica, tudo é absorvido por esse programa da assistência social”.
Embora tenham sido entrevistados gestores de diferentes setores, com diferentes idades e formações, percebeu-se também a falta de conhecimento sobre a PNI. Nas falas dos entrevistados emergiu a dificuldade de entendimento da garantia de articulação intersetorial da PNI no município como responsabilidade de todos enquanto profissionais promovedores de cuidado. Segundo os gestores, as atividades voltadas aos idosos referem-se à procura por atendimento pela "falta de atenção" [E3]. Para o gestor, é por esse motivo que estão sendo realizados projetos direcionados “[...]temos um professor contratado que desenvolve as atividades de ginástica e de dança com eles" [E2]. Ao "projeto" desenvolvido, o gestor atribui à promoção na qualidade de vida dos idosos, pois dessa forma não necessitam fazer uso constante de medicação.

Ao longo das entrevistas, percebe-se a influência da mídia nos discursos dos gestores. Durante os questionamentos, em suas falas, emergiu a influência da mídia enquanto instrumento formador e reprodutor de opinião: "As leis existem, só que os governos prometem e não passam (verbas), os idosos hoje, eles lutam para ficar vivos, porque eles não têm direito nem ao remédio para se manter" [E4].

Em relação a essa influência, percebe-se na fala do mesmo entrevistado os assuntos reproduzidos em mídia, principalmente no que se refere à dificuldade em efetivar ações de cuidado que contemplem a necessidade dos idosos. Esta dificuldade é percebida em todo o país e, pela percepção do entrevistado, reproduz-se no município: "trabalharam, ajudaram o país uma vida inteira, quando eles (idosos) se aposentam, eles têm o direito de escolher ou comer ou tomar remédio" [E4].

Quando discutida a questão do direito à saúde, reitera-se a falta de conhecimento dos gestores, incluindo a necessidade de avanços na política. O entrevistado 3 afirma que é " [...] preciso avançar muito, tanto na questão pública, como na questão de conscientização da própria população [...], questão de preferência em Banco, muitas pessoas acham que não deveria ter preferência, então tem que o idoso passar na frente complicam com isso, mas eu acho que a gente já avançou bastante”. Ao encontro dessa percepção, o entrevistado 6, quando questionado sobre as ações realizadas no município, diz que "está muito aquém ainda, essa questão das especialidades do idoso aqui na região, são vários municípios que também referem isso", dessa forma, percebe-se novamente a relação feita entre o direito ao cuidado como um serviço especializado.

No que tange à política, o entrevistado 5 ainda a relaciona com a existência de Instituições de Longa Permanência para Idosos (ILPI) no município: "Na verdade, não faz muitos anos que foi aplicado (a lei), tinha um lar de idosos". Emerge nessa fala, além da falta de entendimento da PNI, 
a relação do direito enquanto cuidado restrito ao processo de envelhecimento como doença. O mesmo entrevistado reforça sua afirmação dizendo: "Os direitos e os deveres são aquilo, por exemplo, quando foram abertas essas duas casas (ILPI), uma foi até fechada por negligência, por causa da saúde, eu ajudava a fazer alguns consertos lá dentro".

Tabela II - Variáveis relacionadas aos serviços de saúde. Vale do Taquari, RS, 2014.

\begin{tabular}{lcc}
\hline Variáveis relacionadas aos serviços de saúde & $\mathbf{n}$ & $\mathbf{\%}$ \\
\hline Procura por atendimento SUS no município & & \\
Sim & 117 & 87,31 \\
Não & 17 & 12,69 \\
Local em que busca atendimento * & 98 & 73,13 \\
UBS & 56 & 41,79 \\
Secretaria de Saúde & 39 & 29,10 \\
Hospital & & \\
Como avalia o atendimento? & 22 & 16,42 \\
Muito Bom & 80 & 59,70 \\
Bom & 23 & 17,16 \\
Regular & 1 & 0,75 \\
Ruim & 8 & 5,97 \\
Não avaliou & & \\
Sente suas necessidades em saúde contempladas & 41 & 30,60 \\
Sim & 32 & 23,88 \\
Não & 51 & 38,06 \\
Em parte & 10 & 7,46 \\
Não respondeu & & \\
Percepção & 6 & 4,48 \\
Muito boa & 50 & 37,31 \\
Boa & 50,75 \\
Regular & 68 & 4,48 \\
Ruim & 6 & 2,98 \\
Muito Ruim & 4 & \\
\hline
\end{tabular}

*Análise por frequência das respostas.

Tabela III - Associação entre as variáveis analisadas. Vale do Taquari, RS, 2014.

\begin{tabular}{lc}
\hline Variáveis & Valor de p \\
\hline Idade & 0,827 \\
Definição da saúde & 0,770 \\
Atendimento pelo SUS & 0,938 \\
Atividade de saúde e lazer & 0,865 \\
Participação em reuniões & 0,320 \\
Avaliação da atenção & \\
Escolaridade & 0,349 \\
Definição da saúde & $0,010^{*}$ \\
Atendimento pelo SUS & 0,964 \\
Local de atendimento & 0,464 \\
Participação em reuniões & $0,000^{*}$ \\
Avaliação da atenção & \\
Doenças & 0,280 \\
Definição de saúde & 0,831 \\
Avaliação da atenção & \\
Atendimento SUS & 0,650 \\
Definiçãa da saúde & \\
\hline
\end{tabular}


O entrevistado 6 aponta os desafios das ações voltadas à saúde do idoso: "tem muito o que fazer, eu acho, o poder público junto com as entidades, enfim tem muito o que fazer ainda em nível de municipio, a gente tem muito que prosperar nessa área ainda", quando questionado sobre as ações realizadas no município, relacionando a prática com uma ação de conscientização.

Estes desafios apontados pelo gestor refletem no acesso e nas práticas de saúde. O serviço mais acessado pelos idosos é a Unidade Básica de Saúde, sendo que 60\% dos entrevistados avaliam os atendimentos recebidos como bons. Entretanto, 38\% dos idosos referem que a unidade de saúde contempla parcialmente as suas necessidades. Isso reflete também na percepção de saúde do idoso em que a maioria considerou como regular (Tabela II).

A análise estatística dos dados quantitativos aponta resultados significativos entre a escolaridade e a utilização dos serviços de saúde ofertados pela rede pública no município $(p=0,010)$, bem como entre escolaridade e a avaliação da atenção $(\mathrm{p}=0,00)$ (Tabela III).

As dificuldades em entender as propostas da atenção aos idosos por parte dos gestores refletem na disponibilidade das ações. Os gestores entrevistados, em sua maioria, vincularam a responsabilidade das ações ao cuidado de um único profissional. Como se observa na fala do entrevistado 2: "O profissional [...] fez os equipamentos para trabalhar equilibrio, trabalhar força [...] muito bacana". O entrevistado 3 , quando se refere às ações da sua secretaria, afirma "Então nós, diretamente, a nossa secretaria não tem nada voltado e o que a gente sabe é justamente através da assistência, esse trabalho a gente faz".

O entrevistado 6 afirmou que as ações realizadas são fragmentadas, "acontecem ações tanto de prevenção, de reabilitação, de tratamento, só que são ações isoladas,

Tabela IV - Participação na escolha de ações e conhecimentos sobre a PNI dos idosos entrevistados. Vale do Taquari, RS, 2014.

\begin{tabular}{|c|c|c|}
\hline Variáveis & $\mathbf{n}$ & $\%$ \\
\hline \multicolumn{3}{|c|}{ Participacão em grupo de saúde ou lazer oferecido pelo município } \\
\hline Não & 48 & 35,82 \\
\hline Ginástica/Atividade Física & 63 & 47,01 \\
\hline Melhor Idade & 10 & 7,46 \\
\hline Grupo de Encontros CTG & 4 & 2,99 \\
\hline Oficinas & 4 & 2,99 \\
\hline Grupo religioso & 3 & 2,24 \\
\hline Clube de mães & 2 & 1,49 \\
\hline \multicolumn{3}{|l|}{ Dificuldade de deslocamento } \\
\hline Não & 82 & 61,19 \\
\hline Transporte & 36 & 26,87 \\
\hline Deslocamento/Barreiras arquitetônicas & 14 & 10,45 \\
\hline Não respondeu & 2 & 1,49 \\
\hline \multicolumn{3}{|c|}{ Participou de reunião para escolha de ações } \\
\hline Não & 131 & 97,76 \\
\hline Grupo da ginástica & 2 & 1,49 \\
\hline Reunião da secretaria & 1 & 0,75 \\
\hline \multicolumn{3}{|l|}{ Direitos que conhece* } \\
\hline Desconhece & 65 & 48,59 \\
\hline Passe livre & 37 & 27,61 \\
\hline Preferência em filas & 30 & 22,38 \\
\hline Preferência em atendimento em saúde & 10 & 7,46 \\
\hline Medicação gratuita & 10 & 7,46 \\
\hline Respeito/ser bem tratado & 6 & 4,47 \\
\hline Ir e vir & 5 & 3,73 \\
\hline Aposentadoria & 5 & 3,73 \\
\hline Exames gratuitos & 4 & 2,99 \\
\hline Direito à acompanhante em internação & 4 & 2,99 \\
\hline Lazer & 2 & 1,49 \\
\hline Estatuto do Idoso & 2 & 1,49 \\
\hline Vacinas & 1 & 0,75 \\
\hline Acesso à educação & 1 & 0,75 \\
\hline
\end{tabular}

\footnotetext{
*Análise por frequência das respostas.
} 
elas não estão interligadas". Complementa afirmando que o cuidado especializado ao idoso é realizado em grandes centros: "O setor que tu encaminhas, por exemplo, um traumatologista adulto ou uma criança é o mesmo que a gente encaminha um idoso, é para ver questão mesmo que a secretaria leve e busque, às vezes tem que ir junto (com outros pacientes em transporte coletivo); alguns casos (o idoso), é levado de carro".

Embora a PNI garanta o acesso aos serviços de saúde, na percepção dos gestores ela se resume a essa prática. Não foram identificadas nas suas falas ações de promoção à escuta dos idosos, e sua participação na decisão e elaboração de ações ainda não ocorre no município. O entrevistado 4 enfatiza que "é triste ficar velho nesse país".

As ações de promoção configuram-se como uma estratégia importante de manejo do cuidado, tendo em vista que a hipertensão arterial sistêmica (HAS) foi a doença mais frequente, indicada por $65 \%$ dos idosos. Perguntar aos idosos em relação ao seu conhecimento, no que tange à PNI, é um desafio, na medida em que tensiona os idosos a se tornarem protagonistas da sua saúde. A participação social dos idosos restringi-se aos grupos de lazer ou oficinas em diferentes espaços, como Centros de Tradições Gaúchas (CTG) ou grupos religiosos. Já as ações de lazer indicadas pelos idosos referem-se basicamente à ginástica. Destaca-se que $98 \%$ dos idosos dizem não ter participado do planejamento de ações municipais referentes à saúde do idoso (Tabela IV).

A ação de cuidado que a maioria dos gestores relatou ocorrer no município está ligada a grupos divididos por bairros. Nesses grupos são realizadas atividades físicas e dinâmicas, semanalmente, durante aproximadamente uma hora. Um educador físico contratado pelo município coordena as atividades. Antes da sua contratação, a prática era de responsabilidade da Secretaria de Esporte e Lazer, em que uma funcionária coordenava as atividades. Em relação ao preparo para atuação, o entrevistado 2 aponta que a experiência da profissional com a ginástica laboral contribuiu para a realização das ações, pois o profissional deve ter "[...] um pouco de dom, a gente tem que ter um pouco de dom, ela era focada nisso, ela tem simpatia, ela fala em alemão". Sobre a especialidade de atuação com idosos, afirma: "eu gosto dessa área, eu gosto de trabalhar com eles, porque eles te dão um retorno". O entrevistado 2, além de mistificar a ação como sendo uma prática que vem pré-determinada como personalidade, e não como aprimoramento de conhecimento e educação permanente, reflete a ação infantilizada do cuidado quando questionado se tem conhecimento sobre quais são as principais práticas realizadas nos grupos em cada bairro: "as brincadeiras que fazíamos quando criança".
Sobre um grupo de idosos que acontece sem ligação com a gestão, de forma independente, o entrevistado 5 relaciona como sendo projeto do município. Para ele "[...] esses bailezinho é até uma terapia muito boa". Sobre esse grupo, o entrevistado 2 afirma que já foi acompanhado como projeto, no entanto, entendeu que não era essa a proposta quando diz: "para eles (os idosos), não interessava, eles queriam justamente ir para os bailes para dançar, para namorar, e isso envolvia bebida, muitos deles tomavam a cervejinha, a maioria fumava, então fugia um pouco do que era a nossa proposta, de oferecer ainda uma vida saudável para eles".

O entrevistado 2, ao longo do seu relato, também faz afirmações que contradizem a anterior, afirmando que, mesmo com objetivos diferentes do que ele entende por saúde, o lazer proporcionado por esse grupo também pode gerar saúde. A respeito do grupo que ocorre independente da ação municipal, diz que: “[...] Entra um grupo voltado para área não preocupado só com a área de saúde, assim de atividade fisica, é uma área mais de lazer [...], não deixa de ser saúde porque o lazer, a proporção do lazer, gera saúde".

\section{DISCUSSÃO}

A realização do estudo em um município pequeno é relevante para resultados que sejam próximos da realidade em nível nacional, considerando que $61 \%$ dos municípios do país apresentam população inferior a 15.000 habitantes. Esse dado torna-se mais relevante ainda se analisado em nível estadual, uma vez que, no Rio Grande do Sul, 75,4\% dos municípios que o constituem se enquadram nessa descriçãa ${ }^{(13)}$.

Este estudo possibilitou a análise de importantes percepções que emergiram das entrevistas com os gestores. Não menos importante, os questionários respondidos pelos idosos refletem o impacto da falta de conhecimento dos gestores, que influencia diretamente no planejamento e efetivação de ações que contemplem as necessidades da população idosa atendendo às disposições da PNI, sobretudo considerando que não apenas os indicadores socioeconômicos devem embasar as ações, mas a qualidade do cuidado prestado também deve ser avaliada ${ }^{(14)}$. A gestão deve iniciar pela coordenação dos envolvidos mediante independência na tomada de decisões, porém, com consciência de que todos exercem influência entre si, só então será possível o desenvolvimento de atividades ${ }^{(15)}$.

As práticas em atenção à saúde dos idosos requerem preparo tanto dos gestores, os quais são responsáveis pelo planejamento de ações, quanto dos profissionais que irão intervir diretamente com a população. Os cuidados 
em saúde não se restringem a um único profissional ou setor de um município, o cuidado perpassa saberes. Em estudo semelhante, os autores ${ }^{(14)}$ descrevem que um dos contextos que os profissionais da saúde relataram grande dificuldade foi em como compartilhar saberes. Dentre os fatores que os profissionais relataram, destacam-se a "[...] fragilidade do núcleo de competência profissional, a não valorização do seu próprio trabalho, dificuldades pessoais, timidez, imaturidade, medo de errar, disputas de poder, desconhecimento de como trabalhar de forma interdisciplinar, e limitação da formação na graduação"(16). Tendo em vista as características dos gestores analisados no presente estudo, é possível fazer um comparativo no que diz respeito ao preparo profissional. Dos seis entrevistados, apenas um era graduado. Dos demais, apenas um cursava graduação na área da saúde. Ficou claro durante as entrevistas que nenhum dos gestores possuía experiência prévia em gestão anterior à contratação pelo município.

No contexto da falta de conhecimento, percebe-se ações fragmentadas que refletem na forma de atuação profissional. Os entrevistados evidenciaram a concepção de saúde como ausência de doença, relacionando o processo de envelhecimento ao adoecimento. O cuidado, em sua percepção, está ligado ao tratamento de doenças, e os direitos reduzidos à garantia de acesso a exames, consultas e medicações, o que vai de encontro às diretrizes da $\mathrm{PNI}^{(5)}$. Percebe-se, além da falta de conhecimento da PNI, a falta de propostas de promoção de saúde e de ações de cuidado. Na gestão de sistemas de saúde, faz-se necessária a análise da complexidade dos sistemas, o entendimento de que, por se tratar de uma área inovadora, requer o reconhecimento da atuação individual, no entanto, de que o sistema exerce simultaneamente sua influência sobre o comportamento global dentro da complexidade dos cuidados que o compõem. É importante que a rede seja preparada, pois, uma vez que o envelhecimento não é um processo igual para todos, tornase um desafio atender as diferentes necessidades ${ }^{(14,15,17)}$. As mudanças nas práticas ofertadas ao público idoso solicitam um sistema de gestão que priorize o cuidado integral, porém, para tal, a preparação profissional dos atores dessa ação demonstra igual importância na garantia da qualidade do serviço prestado, abrangendo o cuidado preventivo e não apenas o curativo nos programas ofertados aos idosos ${ }^{(18)}$.

Todos os aspectos emergentes nas entrevistas estão diretamente relacionados com a falta de conhecimento da PNI.As Políticas Públicas de Saúde norteiam as necessidades da população de forma generalizada, sendo o conhecimento e entendimento da mesma, combinado com a participação efetiva da população, que proporciona a elaboração de ações eficientes, que atendam às necessidades reais de cada município. Ao encontro do exposto, autores afirmam, a partir de seu estudo, que os sujeitos que compõem o processo de trabalho em saúde são os responsáveis por aproximar ou afastar a ideia de que é possível um novo projeto de cuidado em saúde que tenha por base a integralidade na atenção, e salientam que, para a sua efetivação, é preciso tornar-se um agente de mudanças ${ }^{(16)}$. O profissional da área da saúde, independente da formação, enquanto sujeito integrante do processo de cuidado, deve ter implícita a importância do seu papel como agente promovedor de saúde e cuidado.

Considerando o cuidado como ponto de partida da PNI, vale ressaltar que intervenções direcionadas e ações preventivas contribuem não somente para a qualidade de vida dos indivíduos, mas também corroboram na redução de custos em saúde ${ }^{(19,20)}$. Estudos com expressivo número de idosos ${ }^{(17,21)}$ apontam para a relação da qualidade de avaliação dos determinantes em saúde com a eficiência de práticas de promoção do envelhecimento saudável, dentro de políticas públicas que atendam as necessidades e valorize essa fase do amadurecimento humano.

No cenário internacional, estudo avaliando a saúde no Vietnã ${ }^{(22)}$ destaca os desafios frente a transição demográfica, a preocupação em qualificar os profissionais de saúde para atuação generalizada atendendo os programas de saúde pública do país. Dados sobre as políticas públicas na atenção ao idoso na Colômbia ${ }^{(23)}$ se aproximam das determinações da política do idoso brasileira, no entanto, os pesquisadores concluem que, apesar de descrito os âmbitos legais, a aplicabilidade efetiva é um desafio e importante compromisso de gestores em saúde.

Embora o conhecimento sobre a PNI se faça necessário, igualmente importante é a busca por constante aprimoramento e qualificação profissional de todos os envolvidos nos processos de cuidado, seja ele em saúde, lazer, habitação, assistência social ou demais setores públicos que devem viabilizar e estimular o acesso e participação dos idosos e da população em geral, a escuta é importante na medida em que amplia a qualificação para além do profissional, mas também do serviço e da rede de atenção ${ }^{(24)}$. A educação permanente, enquanto proposta promovedora de transformação, ocorre através da estreita relação entre teoria e prática realizada pelos sujeitos dentro de políticas institucionais que permitam o aprimoramento de ações. As práticas embasadas na educação permanente são promovedoras de alternativas que visam transcender os modos tradicionais de educação ao passo que priorizam atividades que, por sua vez, estão inseridas no contexto histórico, social, econômico, político e ético ${ }^{(14,25)}$.

O presente estudo é potente na medida em que emerge as dificuldades do conhecimento da PNI para a construção de ações efetivas. Entretanto, esta discussão não se encerra em si. Assim como o conhecimento prévio, outro fator que se destaca é a necessidade da educação permanente, da 
qualificação de profissionais e aprimoramento constante. A falta desses requisitos tem impacto direto e negativo nas ações propostas na área da saúde.

O conhecimento teórico, qualificação prática e o planejamento em saúde permitem uma análise criteriosa das situações em saúde. A escuta dos idosos usuários do sistema de saúde também se demonstrou de extrema importância, uma vez que somente ela possibilita o entendimento necessário acerca das necessidades reais da população que se busca contemplar. Além de permitir a elaboração de ações eficientes, reduz custos ao município por ter maior eficácia, especialmente quando inclusos projetos que visem, além da reabilitação e grupos distintos em saúde, a promoção de propostas preventivas que tenham por objetivo a atenção integral ao sujeito, abolindo a fragmentação e a setorização do cuidado.

\section{CONSIDERAÇÕES FINAIS}

A falta de conhecimento dos gestores no que se refere à PNI impacta diretamente nas ações de saúde para esse ciclo de vida no município, reduzindo o direito à saúde desta população ao cuidado restrito ao processo de envelhecimento como doença. Os idosos eram do sexo feminino na sua maioria, com ensino fundamental incompleto, aposentados que usavam unidade básica de saúde e que não identificavam seu papel de controle social para o planejamento de ações que sejam de seu interesse.

\section{REFERÊNCIAS}

1. Instituto Brasileiro de Geografia e Estatística. Censo Demográfico de 2010 [acesso em 2014 Mar 6]. Disponível em: http://www.ibge.gov.br/home/ estatistica/populacao/censo2010/

2. Veras R. Envelhecimento populacional contemporâneo: demandas, desafios e inovações. Rev Saúde Pública. 2009;43(3):548-54.

3. Veras R. Modelos contemporâneos no cuidado à saúde. Rev USP. 2001;51:72-85.

4. Batista AS, Jaccoun LB, Aquino L, El-Moor PD. Envelhecimento e dependência: desafios para a organização da proteção social [Internet]. Brasília: Ministério da Previdência Social; 2008. (Coleção Previdência Social, $\mathrm{n}^{\mathrm{o}} 28$ [acesso em 2014 Mar 6] Disponível em: http://www.previdencia.gov.br/ arquivos/office/3_081208-173354-810.pdf

5. Brasil. Política Nacional do Idoso: Lei $\mathrm{n}^{\circ} .8842$ de janeiro de 1994 [acesso em 2014 Mar 6]. Disponível em: http://www.mds.gov.br/assistenciasocial/secretarianacional-de-assistencia-social-snas/cadernos/politicanacional-do-idoso/politica-nacional-do-idoso

6. Brasil. Lei $\mathrm{n}^{\circ} .10 .741$, de $1^{\circ}$ de outubro de 2003. Dispõe sobre o Estatuto do Idoso e dá outras providências. Diário Oficial da União, Brasília, 3 out. 2003. Seção 1, p. 1.

7. Martins MS, Massarollo MCKB. Mudanças na assistência ao idoso após promulgação do Estatuto do Idoso segundo profissionais de hospital geriátrico. Rev Esc Enferm USP. 2008;42(1):26-33.

8. Rezende M, Moreira MR, Amâncio Filho A, Tavares MFL. A equipe multiprofissional da 'Saúde da Família': uma reflexão sobre o papel do fisioterapeuta. Ciênc Saúde Coletiva. 2009;14(Supl 1):1403-10.

9. Aveiro MC, Aciole GG, Driusso P, Oishi J. Perspectivas da participação do fisioterapeuta no Programa Saúde da Família na atenção à saúde do idoso. Ciênc Saúde Coletiva. 2011;16(1):1467-78.

10. Augusto VG, Aquino CF, Machado NC, Cardoso VA, Ribeiro S. Promoção de saúde em unidades básicas: análise das representações sociais dos usuários sobre a atuação da fisioterapia. Ciênc Saúde Coletiva. 2011;16(1):957-63.

11. Brasil. Portaria $n^{\circ}$. 2.446, de 11 de novembro de 2014. Redefine a Política Nacional de Promoção da Saúde. Brasília: Ministério da Saúde; 2014.

12. Bardin L. Análise de conteúdo. São Paulo: Edições 70; 2011.

13. Medeiros CRG. Redes de atenção em saúde: o dilema dos pequenos municípios [tese]. Porto Alegre: Universidade Federal do Rio Grande do Sul; 2013.

14. Motta LB, Aguiar AC, Caldas CP. Estratégia Saúde da Família e a atenção ao idoso: experiência em três municípios brasileiros. Cad Saúde Pública. 2011;27(4):779-86.

15. Pinheiro FP Filho, Sarti FM. Falhas de mercado e redes em políticas públicas: desafios e possibilidades ao Sistema Único de Saúde. Ciênc Saúde Coletiva. 2012;17(11):2981-90.

16. Scherer MDA, Pires D, Schwartz Y. Trabalho coletivo: um desafio para a gestão em saúde. Rev Saúde Pública. 2009;43(4):721-5.

17. Pilger C, Menon HM, Mathias TAF. Características sociodemográficas e de saúde de idosos: contribuições para os serviços de saúde. Rev Latinoam Enferm. 2011;19(5):1-8. 
18. Almeida STG, Souza MAM, Rodrigues JA, Silva DCO, Nogueira JA, Moreira MAP. Atenção à pessoa idosa: fatores que influenciam o desempenho dos profissionais de saúde na atenção básica. Rev Pesqui Cuid Fundam (Online). 2015;7(Supl):126-35.

19. Rosset I, Roriz-Cruz M, Santos JLF, Hass VJ, Fabrício-Wehbe SCC, Rodrigues RAP. Diferenciais socioeconômicos e de saúde entre duas comunidades de idosos longevos. Rev Saúde Pública. 2011;45(2):391400 .

20. Rosset I, Pedrazzi EC, Roriz-Cruz M, Morais EP, Rodrigues RAP. Tendências dos estudos com idosos mais velhos na comunidade: uma revisão sistemática (inter)nacional. Rev Esc Enferm USP. 2011;45(1):26471.

21. Mantovani EP, Lucca SR, Neri AL. Associações entre significados de velhice e bem-estar subjetivo indicado por satisfação em idosos. Rev Bras Geriatr Gerontol. 2016;19(2):203-22.

22. Hinh ND, Minh HV. Public health in Vietnam: scientific evidence for policy changes and interventions. Glob Health Action. 2013;6:20443.
23. Arango DC, Cardona AMS. Políticas de salud pública aplicadas al adulto mayor en Colombia. Rev Esp Geriatr Gerontol. 2011;46(2):96-9.

24. Martins AB, D'Avila OP, Hilgert JB, Hugo FN. Atenção Primária a Saúde voltada as necessidades dos idosos: da teoria a prática. Ciênc Saúde Coletiva. 2014;19(8):3403-16.

25. Silva LAA, Ferraz F, Lino MM, Backes VMS, Schmidt SMS. Educação permanente em saúde e no trabalho de enfermagem: perspectiva de uma práxis transformadora. Rev Gaúch Enferm. 2010;31(3): 557-61.

\section{Endereço para correspondência:}

Cássia Letícia dos Reis

Av. Avelino Talini, 171

Bairro: Universitário

CEP: 95900-000 - Lajeado - RS - Brasil

Telefone: (51)96901704

E-mail: kciareis@hotmail.com 